\title{
Game-Theoretic Model of the Species and Varietal Composition of Fruit Plantations
}

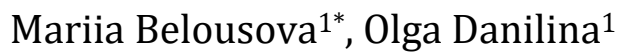 \\ ${ }^{1}$ State University of Management, 99 Ryazansky Prospekt, Moscow, 109542, Russia
}

\begin{abstract}
The horticultural industry is significantly influenced by climatic factors that cannot be accurately predicted. The aim of this study is to substantiate the species and varietal composition of plantations that provide maximum profit, taking into account the attractiveness of the variety and the influence of weather conditions on the results of management. Using the methods of game theory, analysis, and comparison, a game-theoretic model of the species and varietal composition of fruit plantations has been developed. The first matrix of the game contains "pure" strategies that consider only the placement of stone fruits of different ripening periods and "pure" strategies of nature that characterize the possible weather conditions affecting stone fruits. The second matrix of the game consists of "pure" strategies that consider the setting of only pome crops of different ripening periods and "clean" strategies that characterize possible weather conditions affecting the sowing of pome crops. On the basis of the processed material and the calculated indicators, the composition of groups of varieties of pome and stone fruit crops by ripeness for the enterprise is proposed. The results obtained show that the use of a theoretical and game model is effective for the development and selection of the best production solutions under conditions of uncertainty when the production process is highly dependent on random factors.
\end{abstract}

Keywords: Game theory; Gardening; Model; Species and varietal composition; Strategy

\section{Introduction}

At present, mathematical models are increasingly used in various disciplines, such as economics, medicine, and computer science. Also, many studies on mathematical models in the literature elicit scientific interest.

A developed mathematical model of factors driving product success not only examines specific products and scope but also uses a number of standardized success factors by building a mathematical model of the success factors that affect the success of various products (Setyaningrum et al., 2020).

Of interest is a mathematical modeling approach for optimal trade-offs in a wireless sensor network for a grain storage monitoring system (Onibonoje et al., 2019). Surya Admaja and Asvial (2021) proposed a modified routing model based on LEACH with distributing the cluster head to prevent adjacent cluster head from occurring.

Artificial neural networks, commonly referred to simply as neural networks, are one of them today, the most famous and, at the same time, mysterious means of data mining, which is developing thanks to achievements in the fields of neural network theory and

${ }^{*}$ Corresponding author's email: maryzver@gmail.com, Tel.: +7-901-3676563 doi: 10.14716/ijtech.v12i7.5341 
computer science. Transforming seismic data into lateral sonic log properties was carried out successfully using the artificial neural network (Haris et al., 2018).

When developing a strategy under conditions of uncertainty, when random factors have a significant impact on the production process, it is recommended that game-theoretic models be used.

The horticultural industry is significantly influenced by climatic factors (random) that cannot be accurately predicted. At the same time, the most profitable crops suffer the most from the impact of negative weather factors. This situation significantly complicates the selection and justification of design solutions. In these tasks, it is advisable to use a gametheoretic model.

The purpose of the study is to substantiate the species and varietal composition of plantations, which maximize profits, taking into account the attractiveness of the variety and the influence of weather conditions on the results of management.

In game theory, the issues of finding the optimal behavior of participants in a conflict situation are considered. Participants, using certain strategies, strive to achieve maximum effects for themselves. Situation analysis boils down to choosing the best strategies for each participant and determining the amount of winnings. The gain can be a relatively higher efficiency in using resources, production assets, economic levers in production, and economic activities.

Of interest is the use of game theory algorithms for wireless sensor network optimization (Hendrarini et al., 2020). The use of game theory in economics makes it possible to obtain calculations to justify decision-making to improve efficiency (Allayarova et al., 2021). Game theory is used to solve real and current economic problems in different spheres of the economy. Therefore, a number of scientists have been engaged in developing the optimal strategy for the development of insurance business structures in a competitive environment (Yurynets et al., 2020). The designed game theory model allows the insurance company's executives to determine the favorable insurance market conditions.

Of interest is the application of the theory of differential games in military affairs and economics (Korolyov, 2018). The article shows how the problem of differential economicmathematical game arises from the simplest problems of classical variational calculus. Sufficient conditions for the Pontryagin Mangasarian maximum and their applications to the study of economic problems are investigated. Game theory and its optimum application for solving economic problems are discussed in Durmanov et al. (2019). However, this work does not reflect the peculiarities of the horticultural industry.

Agricultural production depends on a number of risks, such as soil, weather, climate conditions, seeds, price difference, organisms, and diseases. To reduce agricultural risks, the apparatus of game theory is used. Scientists researched the uppermost expected income of the lowest expected outcome earned from studying products in the worst conditions and the uppermost output in the lowest time with minimum investments (Kashid, 2017).

Tursunov et al. (2020) examined the question of for which products it is better to start the creation and development of small business in the agricultural sector (namely, growing vegetables) and what behavior helps reduce losses using the methods of game theory.

The problem of applying game theory for optimal cultivation of vegetables and fruits in the greenhouse is devoted to the work of Umarov et al. (2021). However, in this work, the optimal production structure was not presented, which would provide maximum profit.

In the study of Setyowati et al. (2021), choices of strategic alternatives are choices in determining which horticulture commodities will be grown: potato, cabbage, or scallion. However, this work did not reflect the peculiarities of the species and varietal composition of fruit plantations (Setyowati et al., 2021). 


\section{Methods}

Each formalized game is characterized by the following:

- The number of actors involved in the conflict

- A possible set of actions (strategies) for each participant

- Functions of gain, reflecting the degree of satisfaction of interests

- The result of the game, to which the chosen strategies lead

Formalization of a conflict situation in the form of a game consists in describing its main elements. The active player in this case is the decision-maker; the passive one is nature.

We can construct the estimation functional based on the following information:

- The possibility of the onset of various weather conditions

- Yield levels of perennial plantings, which are formed under the influence of these weather conditions

- Costs of production and sale of fruits

- Fruit sales prices

According to the game-theoretic model, it is necessary to substantiate the composition of the plantations that minimizes the risk of loss of profit, taking into account the investment attractiveness of fruit crops.

Since climatic conditions affect stone and pome fruit crops in different ways, it is necessary to draw up two matrices. The first matrix should contain "pure" strategies that take into account only the setting of stone fruits of different ripening periods and "pure" strategies of nature that characterize possible weather conditions affecting stone fruit crops. The second matrix of the game should include "pure" strategies that consider the setting of only pome crops of different ripening periods and "pure" strategies that characterize possible weather conditions affecting the plantings of pome crops.

"Clean" enterprise strategies for composing the first matrix: "Clean" enterprise strategies for compiling the first matrix: $x_{k}, k=\overline{1,15}$ (Table 1 ).

Below are the possible weather conditions, $q_{j}, j=\overline{1,6}$, affecting stone fruit perennial plantings:

- Temperature $-4^{\circ} \mathrm{C}$ and below in the pink bud phase $\left(q_{1}\right)$

- Temperature $-0.6-2^{\circ} \mathrm{C}$ and below during flowering $\left(q_{2}\right)$

- Excessive precipitation in the period from the third decade of May to the first decade of July $\left(q_{3}\right)$

- Drought during the growing season $\left(q_{4}\right)$

- Winter frosts from above $-30^{\circ} \mathrm{C}\left(q_{5}\right)$

- Weather conditions that are favorable for these crops $\left(q_{6}\right)$

Probability, $q_{j}, j=\overline{1,6}$, the onset of various weather conditions, and their effect on the level of stone fruit yield are determined by the data of meteorological stations and by fluctuations in the yield levels of perennial plantations.

For the second matrix, consider the "pure" enterprise strategies $x_{k}, k=\overline{1,6}$ (Table 2). 
Table 1 "Clean" strategies that take into account the setting of stone fruits of different ripening periods

\begin{tabular}{cl}
\hline Conditional designation & \multicolumn{1}{c}{ Enterprise strategies } \\
\hline$x_{1}$ & Laying early varieties of sweet cherries \\
$x_{2}$ & Laying of cherry varieties of medium maturity \\
$x_{3}$ & Laying of late ripening cherry varieties \\
$x_{4}$ & Laying of early varieties of apricot \\
$x_{5}$ & Setting of medium-ripening apricot varieties \\
$x_{6}$ & Laying of late-ripening apricot varieties \\
$x_{7}$ & Laying of plantings of early-ripening cherry varieties \\
$x_{8}$ & Laying of mid-season cherry plantations \\
$x_{9}$ & Laying of plantings of late-ripening cherry varieties \\
$x_{10}$ & Laying of early maturing peach varieties \\
$x_{11}$ & Laying of mid-season peach plantations \\
$x_{12}$ & Laying of plantings of late-ripening peach varieties \\
$x_{13}$ & Planting early-ripening plum varieties \\
$x_{14}$ & Laying of mid-season plum plantations \\
$x_{15}$ & Laying of plantations of late-ripening plum varieties \\
\hline
\end{tabular}

Table 2 "Pure" strategies that take into account the setting of pome crops of different ripening periods

\begin{tabular}{cl}
\hline Conditional designation & \multicolumn{1}{c}{ Enterprise strategies } \\
\hline$x_{1}$ & Laying of plantings of apple trees of summer varieties \\
$x_{2}$ & Laying of plantings of apple trees of autumn varieties \\
$x_{3}$ & Laying of plantings of apple trees of winter varieties \\
$x_{4}$ & Laying of plantings of summer pears \\
$x_{5}$ & Laying of plantings of pears of autumn varieties \\
$x_{6}$ & Laying of plantations of winter pears \\
\hline
\end{tabular}

Below are the possible weather conditions, $q_{j}, j=\overline{1,6}$, to compose the second matrix:

- Temperature $-4^{\circ} \mathrm{C}$ and below in the pink bud phase $\left(q_{1}\right)$

- Temperature $-0.6^{\circ} \mathrm{C}$ and below during flowering $\left(q_{2}\right)$

- Sharp drops in temperature in autumn $\left(q_{3}\right)$

- Thaws in winter with temperatures $0 \ldots+4{ }^{\circ} \mathrm{C}\left(q_{4}\right)$

- Winter frosts from above $-30^{\circ} \mathrm{C}\left(q_{5}\right)$

- Weather conditions that are favorable for these crops $\left(q_{6}\right)$

Probability, $q_{j}, j=\overline{1,6}$, the onset of various weather conditions, and their effect on the level of the yield of pome fruit are determined as for the first matrix. 


\section{Results and Discussion}

As a result of the influence of weather factors, the following are possible: shortage of a significant part of the crop due to winter frosts, loss of the overwhelming part of the crop during frosts in the rosebud phase and during the flowering period, loss of an insignificant part of the cherry and cherry harvest due to excessive rainfall during the ripening period, and obtaining the maximum possible yield (Table 3). In the presence of irrigation systems, drought during the growing season will not affect the level of fruit yields but will lead to an increase in production costs and a decrease in product prices due to a deterioration in taste.

Table 3 The yield of stone fruits under various weather conditions for the Krasnodar Territory, (centner/ha)

\begin{tabular}{ccccccc}
\hline \multirow{2}{*}{$\begin{array}{c}\text { Species and varietal } \\
\text { composition }\end{array}$} & $q_{1}$ & $q_{2}$ & $q_{3}$ & $q_{4}$ & $q_{5}$ & $q_{6}$ \\
\cline { 2 - 7 }$x_{1}$ & 0.13 & 0.26 & 0.25 & 0.05 & 0.01 & 0.3 \\
\hline$x_{2}$ & 2.9 & 2.9 & 48,8 & 57.4 & 2.9 & 57.4 \\
$x_{3}$ & 6.3 & 9.0 & 76.2 & 89.6 & 4.5 & 89.6 \\
$x_{4}$ & 8.8 & 8.8 & 74.4 & 87.5 & 4.4 & 87.5 \\
$x_{5}$ & 3.4 & 3.4 & 67.9 & 67.9 & 3.4 & 67.9 \\
$x_{6}$ & 8.4 & 4.2 & 84 & 84.0 & 6.7 & 84.0 \\
$x_{7}$ & 9.1 & 9.1 & 101.5 & 101.5 & 10.2 & 101.5 \\
$x_{8}$ & 3.3 & 3.3 & 55.3 & 65.0 & 6.5 & 65.0 \\
$x_{9}$ & 3.6 & 7.2 & 60.8 & 71.5 & 7.2 & 71.5 \\
$x_{10}$ & 3.2 & 6.3 & 53.6 & 63.1 & 6.3 & 63.1 \\
$x_{11}$ & 7.0 & 7.0 & 140.7 & 140.7 & 1.4 & 140.7 \\
$x_{12}$ & 5.3 & 10.6 & 105.7 & 105.7 & 1.1 & 105.7 \\
$x_{13}$ & 7.2 & 14.5 & 144.9 & 144.9 & 1.4 & 144.9 \\
$x_{14}$ & 5.6 & 4.0 & 80.5 & 80.5 & 8.1 & 80.5 \\
$x_{15}$ & 7.6 & 7.6 & 75.5 & 75.5 & 7.6 & 75.5 \\
\hline & 8.9 & 8.9 & 89 & 89.0 & 8.9 & 89.0 \\
\hline
\end{tabular}

Under the influence of weather factors, a possible shortage of an insignificant part of the crop (in cases of sudden temperature changes in autumn, thaws lasting more than five days in winter) and the loss of the overwhelming majority of it (with frosts in the rosebud phase and during the flowering period) occur. In contrast to the previous matrix, the impact on the level of precipitation yield is not considered since the cultivation of pome fruits in the Krasnodar Territory is expedient only in the presence of irrigation systems (Table 4).

The profit (loss) from the sale of stone fruits per 1 ha is determined in comparable prices in 2020. When calculating the profit, we take into account the increase in the price level due to the reduction in the supply of fruits, the decrease in prices for cherries, and cherries with excessive precipitation in the period from the third decade of May to the third decade of June, resulting in very low commercial quality of the fruit.

According to the results of calculations, the highest level of profitability in the case of significant precipitation in the period from the third decade of May to the third decade of June, drought during the growing season, and favorable climatic conditions ensure the 
cultivation of peaches, especially varieties of late ripening.

Table 4 Productivity of pome fruits under different weather conditions for the Krasnodar Territory, (centner/ha)

\begin{tabular}{ccccccc}
\hline \multirow{2}{*}{$\begin{array}{c}\text { Species and varietal } \\
\text { composition }\end{array}$} & $q_{1}$ & $q_{2}$ & $q_{3}$ & $q_{4}$ & $q_{5}$ & $q_{6}$ \\
\cline { 2 - 7 } & 0.07 & 0.14 & 0.15 & 0.2 & 0.01 & 0.43 \\
\hline$x_{1}$ & 7.4 & 8.9 & 103.4 & 88.6 & 14.8 & 147.7 \\
$x_{2}$ & 8.7 & 10.5 & 122.0 & 104.5 & 17.4 & 174.2 \\
$x_{3}$ & 9.2 & 11.0 & 110.2 & 119.3 & 18.4 & 183.6 \\
$x_{4}$ & 7.9 & 9.5 & 110.7 & 94.9 & 15.8 & 158.2 \\
$x_{5}$ & 9.6 & 11.5 & 134.3 & 115.1 & 19.2 & 191.8 \\
$x_{6}$ & 8.4 & 10.3 & 101.2 & 109.7 & 16.9 & 168.7 \\
\hline
\end{tabular}

At the same time, under unfavorable weather conditions (frosts in the pink bud phase and during the flowering period, winter frosts above $-30^{\circ} \mathrm{C}$ ), peach cultivation leads to the greatest losses.

Based on the calculations, we can conclude that the cultivation of peach will ensure the complete use of weather conditions and, thereby, obtain the greatest profits in cases of excessive moisture, drought during the growing season, and favorable weather conditions for stone fruit cultivation. The laying of apricot stands is minimal, in comparison with other crops, losses during winter frosts above $-30^{\circ} \mathrm{C}$, and late spring frosts.

A game-theoretic model is applied to determine the species and varietal composition of plantings, which will maximize profits at LLC "Experimental - industrial facilities named after K.A. Timiryazev". According to the results of calculating Bayesian estimates for the corresponding solutions for a group of stone fruits, a clean strategy is optimal for a horticultural enterprise $x_{12}$-laying of stands of peach of late ripening, and in the second and third places, respectively, - -laying of stands of peach of early and medium ripening.

Decisions $x_{1}, x_{7}, x_{8}, x_{9}, x_{13}, x_{14}$, and $x_{15}$-growing, respectively, cherries of an early ripening period, cherries and plums are impractical, since $M\left(F_{1}\right), M\left(F_{7}\right), M\left(F_{8}\right), M\left(F_{9}\right)$, $M\left(F_{13}\right), M\left(F_{14}\right)$, and $M\left(F_{15}\right)$ have negative values.

For the group of pome crops, according to this criterion, the optimal strategy is to lay winter apple varieties in descending order of the rating: autumn apple varieties, autumn and winter pear varieties, and summer pome varieties.

According to the criterion of minimum variance, for stone fruit, the best solution is $x_{13}$ - growing plums of an early ripening period, then in descending order of rating: cherries of a late ripening period, plums of late and medium ripening periods, cherries of an early and medium ripening period, apricot of an early ripening period, cherries of an early and late ripening period, apricot of late and medium ripening periods, cherries of medium ripening, and peaches of medium, early, and late ripening; for pome fruits-growing summer varieties of pears, then in descending order of rating: summer and autumn varieties of apple trees, winter and autumn varieties of pears, and winter varieties of apple trees.

In the case under study, of all possible conditions of weather conditions, the most 
probable is "favorable weather conditions" $\left(q_{6}=0.3\right)$. Optimal for the enterprise, according to the modal criterion, is the establishment of late ripening peach stands. Insofar as $M o(Q)=q_{6}$, then unfavorable deviations satisfy the condition: $f\left(x_{k}: q_{j}\right)<f\left(x_{k} ; \operatorname{Mo}(Q)\right)=f\left(x_{k} ; q_{6}\right)$.

According to the criterion of the minimum expected value of unfavorable deviations from fashion, the best solution is to grow early ripening plums, then in descending order of rating: late ripening cherries, late and medium ripening plums, early ripening cherries and apricots, and early and medium ripening cherries, middle and late ripening cherries. The worst option, which will provide the most unfavorable deviations, that is, the highest level of risk, is the cultivation of a peach.

For pome crops, of all possible weather conditions, the most probable is "favorable weather conditions," $q_{6}=0,43$.

Then, the optimal for the enterprise, according to the modal criterion, is the laying of winter varieties of apple trees.

According to the criterion of the minimum expected value of unfavorable deviations from fashion, the best option should be considered the cultivation of summer varieties of apple trees and the worst-autumn varieties of pears.

In the next step, for each solution option for stone fruit, a matrix of unused opportunities was built, showing the amount of lost profit compared to the maximum possible under the given weather conditions.

According to the research results, we conclude that the laying of apricot stands of medium and late ripening periods will provide the minimum possible losses under three possible weather conditions (winter and late spring frosts), the total probability of which is $40 \%$; the worst results under these conditions are peach plantations. The fullest use of other possible weather conditions (in $60 \%$ of cases) will ensure the establishment of late ripening peach stands. Under these weather conditions, the largest amounts of lost income are observed in the presence of plantations of cherry, plum, and early varieties of sweet cherry.

Taking into account the likelihood of the onset of various weather conditions, according to this criterion, the best solution is laying peach stands, and after this, it is apricot of late and medium ripening periods. The less attractive is early apricot and cherries of medium and late ripening periods, and the least attractive is laying of plantings of cherries and plums.

In the next stage, for each solution option for pome crops, a matrix of unused opportunities was built, showing the amount of lost profit compared to the maximum possible under the given weather conditions.

According to the calculations, in conditions of unprofitable production, alternative possibilities are not used to the greatest extent in the presence of plantings of apple trees of summer and winter varieties. In the conditions of profitable production (favorable and moderately favorable weather conditions), alternative opportunities are used unsatisfactorily in the presence of plantings of pear and apple trees of summer varieties.

Taking into account the probability of the onset of various weather conditions, the best "clean strategy" would be to plant plantations of winter apple trees, then apple and pear autumn varieties, winter pears, and the worst options-summer pear and apple trees.

Thus, the results of the assessment by different criteria do not coincide, and the establishment of plantings of different types will minimize the risk and guarantee positive results under different weather conditions. Therefore, the next step will be to determine the proportions in which it is necessary to plant plantings to minimize losses, regardless of 
weather conditions.

On the basis of the processed material and the calculated indicators, we offer the structure of the areas of perennial plantings. Taking into account the existing marketing channels and the presence and capacity of fruit storage, the share of pome crops should be $55 \%$, and that of stone fruit should be $45 \%$ (Table 5).

Table 5 Recommended structure of groups of varieties of pome and stone fruit crops by maturity in LLC n. K.A. Timiryazeva

\begin{tabular}{lcrr}
\hline \multicolumn{1}{c}{ Cultures } & $\begin{array}{c}\text { The actual structure of the } \\
\text { areas of young plantations }\end{array}$ & Estimated option & Deviation \\
\hline Pome fruit, of which: & 21.3 & 45.1 & 23.8 \\
Apple tree total & 17.3 & 31.5 & 14.2 \\
Summer varieties & 3.1 & 4.1 & 1.0 \\
Autumn varieties & 5.2 & 14.5 & 9.3 \\
Winter varieties & 9.0 & 13.0 & 4.0 \\
\hline Pear total & 3.9 & 13.6 & 9.7 \\
Summer varieties & 0.8 & 1.3 & 0.5 \\
Autumn varieties & 1.2 & 8.6 & 7.4 \\
Winter varieties & 2.0 & 3.7 & -23.8 \\
Stone fruits, of which: & 78.7 & 54.9 & -58.2 \\
Cherry total & 66.9 & 8.7 & -13.3 \\
Early maturing varieties & 13.4 & 0.1 & -27.3 \\
Mid-season varieties & 33.5 & 6.2 & -17.7 \\
Late-ripening varieties & 20.1 & 2.4 & 10.9 \\
Apricot total & 2.4 & 13.3 & -0.3 \\
Early maturing varieties & 0.5 & 0.2 & 7.4 \\
Mid-season varieties & 1.2 & 8.6 & 3.9 \\
Late-ripening varieties & 0.7 & 4.6 & 23.4 \\
Peach total & 9.4 & 32.8 & 4.6 \\
Early maturing varieties & 3.3 & 7.9 & 12.4 \\
Mid-season varieties & 2.4 & 14.8 & 6.3 \\
\hline Late-ripening varieties & 3.8 & 10.1 & 0.0 \\
\hline Total & 100.0 & 100.0 & \\
\hline
\end{tabular}

As a result of calculations, it is recommended to increase the share of pome crops by $23.8 \%$, among them apples by $14 \%$ and pears by $9 \%$. Among stone fruit crops, reduce the share of cherries by $58 \%$, increase the share of apricots by $10.3 \%$, and increase the share of peaches by $23.4 \%$.

As a result of the project, the profitability index will be 1.51, and the degree of project sustainability will be $28.1 \%$. The proposed project will minimize the risk of losing profits as a result of the loss of crops from unfavorable weather conditions, but it will not maximize profits under favorable weather conditions. Considering the rather high probability of unfavorable weather conditions ( $22 \%$ for pome fruits, $40 \%$ for stone fruits), according to the ratio "expected effect from the implementation of the project-the level of risk," this project is characterized by an average level of efficiency and a moderate level of risk (in comparison with other projects in horticulture).

Optimization of the breed and varietal composition is the main measure used to minimize the risks of crop loss from unfavorable weather conditions. However, in addition to this, to reduce risks, horticultural enterprises need to introduce agrotechnical measures to protect fruit plantations from frost damage, ensure plantings, and the like.

The possibility of using game theory in the tasks of the organizational and economic mechanism of the greenhouse is supported by previous studies (Durmanov et al., 2019; Umarov et al., 2021). With the help of game theory, the problem of optimal cultivation of vegetables and fruits in a greenhouse has been solved. The authors proved that the 
application of game theory contributes to the successful development of greenhouses.

The current results are supported by previous research that used game theory to determine what goods will be grown by farmers (Setyowati et al., 2021). The authors used game theory to analyze the decisions made by horticultural farmers when determining which horticultural products are best to plant according to their behavior and attitudes toward the risks associated with farming.

\section{Conclusions}

Summing up the study, we can formulate the following conclusions:

The horticulture industry is significantly influenced by climatic factors that cannot be accurately predicted. At the same time, the most profitable crops are bones of early and middle maturation, which are most affected by negative weather factors.

When developing a strategy in conditions of uncertainty when random causes have a significant impact on the production process, it is advisable to use a theoretical game model. The use of the theoretical and game model made it possible to determine the breed-grade composition of plantations, which ensures the maximization of profit, taking into account the attractiveness of the variety and the influence on the results of weather management.

Possible extensions for future research may include dynamic aspects or multi-objective functions.

\section{References}

Allayarova, S., Kilichevab, F., Rakhimovac, K., Mamasadikovd, A., Khamrayevae, S., Durmanov, A. 2021. Game Theory and Its Optimum Application for Solving Economic Problems. Turkish Journal of Computer and Mathematics Education, Volume 12(11), pp. 3432-3441

Durmanov, A., Tulaboev, A., Li, M., Maksumkhanova, A., Saidmurodzoda, M., Khafizov, O. 2019. Game Theory and Its Application in Agriculture (Greenhouse Complexes). In: 2019 International Conference on Information Science and Communications Technologies (ICISCT), pp. 1-7

Haris, A., Murdianto, B., Susattyo, R., Riyanto, A., 2018. Transforming Seismic Data into Lateral Sonic Properties Using Artificial Neural Network: A Case Study of Real Data Set. International Journal of Technology, Volume 9(3), pp. 472-478

Hendrarini, N., Asvial, M., Sari, R.F., 2020. Energy Balanced Threshold using Game Theory Algorithm for Wireless Sensor Networks Optimization. In: Proceedings of the $3^{\text {rd }}$ International Conference on Software Engineering and Information Management (ISCIM-2020), pp. 165-169

Kashid, U.S., 2017. Application of Game Theory Model to Selecting Management Strategies for Optimization Resources in Agricultural Field. International Journal of Advance Research in Science and Engineering, Volume 6(1), pp. 1108-1117

Korolyov, I.V., 2018. Differential Game Theory Application in Models of Trade Relations of Great Britain with Portugal and Russia with Belarus. Upravlenie, Volume 6(2), pp. 4551

Onibonoje, M.O., Ojo, A.O., Ejidokun, T.O., 2019. A Mathematical Modeling Approach for Optimal Trade-Offs in a Wireless Sensor Network for a Granary Monitoring System. International Journal of Technology, Volume 10(2), pp. 332-338

Setyaningrum, R., Subagyo, Wijaya, A.R., 2020. A Mathematical Model of Factors Driving Product Success in an Indonesian Market using Design of Experiment. International Journal of Technology, Volume 11(2), pp. 322-332 
Setyowati, P., Toiba, H., Sujarwo, S., Syafrial, S., Nugroho, C., 2021. Game Theory Application in Decision Making of Horticulture Farming. Agricultural Socio-Economics Journal, Volume 21(1), pp. 59-64

Surya Admaja, A.F., Asvial, M., 2021. LEACH Distributed Clustering Improvement for Wireless Sensor Networks. ECTI-CON 2021, pp. 98-101

Tursunov, I., Yangiboyev, B., Babadjanov A., Tabaev, A., Durmanov, A., 2020. Application of Mathematical Theory Games When Decision on the Creation Small Business in the Agricultural Industry Republic of Uzbekistan. Solid State Technology, Volume 63(4), pp. 325-333

Umarov, S., Durmanov, A., Li, M., Khushvaktova, K., Yakubova, K., Shanasirova, N., 2021. Features of the Application of Game Theory in the Tasks Organizational and Economic Mechanisms Greenhouse Economy. Turkish Journal of Computer and Mathematics Education, Volume 12(11), pp. 3544-3550

Yurynets, R., Yurynets, Z., Myshchyshyn, I., Zhyhaylo, N., Pekhnyk, A., 2020. Optimal Strategy for the Development of Insurance Business Structures in a Competitive Environment. In: Proceedings of the $2^{\text {nd }}$ International Workshop on Modern Machine Learning Technologies and Data Science (MoMLeT+DS 2020), Volume I, pp. 79-94 